Article

\title{
Analysis of Daily Load Patterns Taking into Consideration PEVs Charging Stations in Seoul, South Korea
}

\author{
Sangbong Choi ${ }^{1, *}$, Changsoo Kim $^{1}$ and Backsub Sung ${ }^{2}$ \\ 1 Power Grid Research Division, Korea Electrotechnology Research Institute (KERI), Changwon 51543, Korea; \\ cskim@keri.re.kr \\ 2 Department of Mechanical Engineering, Chosun University, Gwangju 61452, Korea; sbsung@hanmail.net \\ * Correspondence: sbchoi@keri.re.kr; Tel.: +82-31-280-1361
}

Citation: Choi, S.; Kim, C.; Sung, B. Analysis of Daily Load Patterns Taking into Consideration PEVs Charging Stations in Seoul, South Korea. Energies 2021, 14, 2662. https://doi.org/10.3390/en14092662

Academic Editor: Joao Ferreira

Received: 17 March 2021

Accepted: 29 April 2021

Published: 6 May 2021

Publisher's Note: MDPI stays neutral with regard to jurisdictional claims in published maps and institutional affiliations.

Copyright: (c) 2021 by the authors. Licensee MDPI, Basel, Switzerland. This article is an open access article distributed under the terms and conditions of the Creative Commons Attribution (CC BY) license (https:// creativecommons.org/licenses/by/ $4.0 /)$.
Abstract: This paper presents a methodology to calculate daily charging load curves in Seoul, South Korea, by taking into account plug-in electric vehicles (PEVs) charging stations, allowing Seoul's government to determine the PEVs charging effect on the load. In particular, the study calculates the charging power of uncontrolled PEVs charging in terms of the daily operating characteristics of a vehicle traveling between home and workplace, with respect to PEVs charging stations in the city, according to the PEVs' market share. For the controlled PEVs charging strategy based on morning and afternoon work-to-home and vice versa traffic characteristics and time-of-use (TOU) prices in Seoul, the study calculates daily load patterns of uncontrolled and controlled charging scenarios. After adding the calculated values to the existing load, the study assesses and compares their effects on the power grid. The results are as follows. If by 2030 the share of electric vehicles is $10 \%$, compared to the existing load, the total load increases by about 13\% between 9:00 and 11:00 in the morning for the uncontrolled mode and by about $10 \%$ for the controlled mode. The total load increases by about 16\% between 20:00 and 22:00 for the uncontrolled mode and 17\% for the controlled mode. However, if by 2040 the share of electric vehicles is 30\%, compared to the existing load, the total load increases by about 35\% between 9:00 and 11:00 in the morning for the uncontrolled mode and by about 32\% for the controlled mode. Between 20:00 and 22:00, the uncontrolled mode's total charging load increases by about $35 \%$ and the controlled mode's total load by about $32 \%$. The analysis also demonstrated that it was possible to achieve a significant load-leveling effect in all charging periods for the controlled mode, with the daily load pattern's average leveling rate increasing by $8 \%$ and $13 \%$ in 2030 and 2040, respectively, based on the TOU price system compared with the uncontrolled mode. Based on these results, it is possible to determine the PEVs' hourly charging load effect on the power grid in Seoul and establish a PEVs charging load management plan to prevent the power grid reinforcement and expansion and to satisfy its overload constraint by using an appropriate TOU price plan.

Keywords: daily load patterns; charging station; controlled PEVs; uncontrolled PEVs; time of use (TOU)

\section{Introduction}

Efforts are made worldwide to increase the use of plug-in electric vehicles (PEVs) as a solution for air pollution problems caused by $\mathrm{CO}_{2}$ emissions, owing to the increasing number of fuel-powered vehicles. Thus, the number of grid-connected charging stations for PEVs is expected to grow exponentially in the future, potentially creating a burden for power companies. Various studies estimated the power demand for PEVs battery charging and accurately assess whether existing distribution systems can cope with the increasing charging power demand. These studies were supported by governments through technical standards and transaction regulations concerning PEVs, to prepare for PEVs expansion around the world.

From the viewpoint of distribution utilities, the impact of spatial-temporal changes in loads from PEVs at a distribution system on the overload of the line and bus should be 
analyzed. To accurately calculate the effect of PEVs loads on the distribution line and bus, a detailed system evaluation considering alteration based on the nature of PEVs loads is required [1].

Various papers have been conducted to calculate the universal effect of PEVs on the distribution system. Kejun et al. [2] proposed a method to evaluate the load demand of the distribution system according to the PEVs charging based on charging modeling. ClementsNyns et al. [3] calculated the system loss when the PEVs is charged in a home or a parking garage and its efficacy on the distribution line from the standpoint of voltage change. Zhao et al. [4] developed a method on the basis of an inclusive model for calculating effect of PVEs on the distribution line. Son and Kook [5] proposed a stochastic modeling of PEVs charging in distribution systems and evaluated the relevant clustering nature.

However, in the paper mentioned above [5], they evaluated PEVs clustering just by considering the number of PEVs by family and applying the stochastic method, thereby failing to mirror the charging nature per battery type and the charging time, which are reflected more critical than the number of PEVs, while calculating the charging effect on the distribution line and bus. In addition, Choi [6] completed a load analysis of each bus of the distribution system based on PEVs' charging modeling in new towns. In another study, Choi [7] conducted a voltage drop analysis of each bus of the distribution system through PEVs' charging modeling in new towns. In addition, Liu and Wen [8] conducted a study focusing on selecting optimal locations for PEVs' charging stations. The studies listed above mainly dealt with the problems of voltage drop and load by power bus on distribution systems based on PEVs' charging modeling in new towns. While focusing on determining optimal charging locations, these studies' drawback is that they did not demonstrate a method for calculating daily load patterns by taking into account the charging locations of PEVs in large cities like Seoul.

In particular, there are not many studies on the electric vehicle charging TOU tariffs, which are necessary to minimize the impact of PEVs charging on the distribution system. There is insufficient research on how smooth the daily load patterns of a metropolitan area grid are due to charging electric vehicles based on the TOU tariff system.

There are some modeling studies on the TOU tariff systems to minimize the PEV charging costs in the regulated market $[9,10]$ and research on reducing the impact of electric vehicle charging on the grid [11,12]. Most research is limited to suggesting sequential charging, decreasing power loss, reducing charging fees for PEVs owners, TOU strategies for peak reduction, and charging management at PEVs charging stations using ESS (Energy Storage System). There is no analysis on the effectiveness of the grid's daily load pattern flattening due to charging electric vehicles in large metropolitan areas based on the TOU tariff system.

To resolve these problems, assessing the PEVs' charging effect on large metropolitan areas in the national power grid is essential. To this end, effect-assessment modeling based on the PEVs charging per charging station must be developed. Because most drivers of PEVs in urban areas use their vehicles to commute only between home and workplace, they charge their vehicles at the workplace and at home after work. Therefore, a study modeling the effect of PEVs charging per charging station (such as at home and in the workplace) on the power grid is needed.

This study developed a method to calculate the PEVs charging per charging station in a metropolitan area. It calculates the daily load patterns of PEVs charging in Seoul based on PEVs charging conditions and the number of PEVs based on their predicted increased market share in 2030 and 2040.

\section{Daily Load Patterns Calculation Methodology}

This study develops a method to calculate PEVs daily charging load curves based on charging stations in large cities. In more detail, first, based on the Seoul Metropolitan Government's PEVs market share policy scenario for 2030 and 2040, the study calculates the PEVs daily charging load curves for the uncontrolled charging mode (taking into account 
the number of vehicles operated per hour) based on the number of vehicles operated and charging stations (in the workplace in the morning and at home in the afternoon and in the evening). Second, the study calculates the PEVs daily charging load curves for the controlled charging mode that considers the TOU price plan and the number of vehicles operated per hour. Third, after calculating the daily charging load curves for the uncontrolled and controlled modes in Seoul for the relevant year, the study proposes a method of adding these calculations to the existing daily load patterns. This method is described step-by-step below.

1. Calculate the probability density function for the uncontrolled PEVs charging start time at work and home.

2. Calculate the probability density function for the controlled PEVs charging start time in the workplace and at home.

3. Calculate the initial state of charge (SOC) status for electric vehicle batteries at work and at home.

4. Calculate the PEVs charging power by time intervals using the uncontrolled and controlled PEVs charging probability density function and the initial SOC status of PEVs batteries in the workplace and at home.

5. Calculate the daily load patterns for PEVs charging in Seoul based on the charging load result in accordance with the annual PEVs share scenario for uncontrolled and controlled PEVs charging times in the workplace and at home. Then, add that to the existing daily load patterns.

Because the developed algorithm can precisely determine the daily load patterns of the PEVs charging load in the workplace and at home, this method can be used to establish a charging TOU tariff plan management approach to prevent the overload of the power grid in Seoul.

\subsection{Charging Model per PEVs Charging Station}

This study used the data from the Seoul Metropolitan Police Agency Traffic Information Center [13] to determine the traffic entering and exiting downtown Seoul and analyze the PEVs charging stations' effect on the power grid. The results indicated that traffic entering the downtown area for work peaked from 7:00 to 9:00 in the morning. However, the traffic leaving the downtown area after work started to increase from 17:00 and peaked at 20:00; then it gradually decreased until late at night (Figure 1).

It is possible to use the downtown Seoul traffic entry data as morning work traffic data. The probability density function for PEVs charging start time upon arrival at work can be calculated. The downtown Seoul traffic exit data can be used as going-home- after-work traffic data. Thus, the probability density function for the PEVs charging start times upon arrival at home can be calculated.

When calculating the probability density function for the charging start time by PEVs charging location, a charging model was established by dividing charging into the controlled mode, reflecting the TOU price [14], and the uncontrolled mode. However, this study used specific time interval data for the probability density modeling of the charging time for each PEVs charging place.

The reason is that in Seoul most chargers are at home or work compared to other locations. Because the default charging strategy is set to avoid peak times (time intervals 12-15), this study assumed that the charging intervals were from 4:00 to 11:00 at work and from 16:00 to 23:00 at home. Considering the commuting distances in Seoul, this study assumed that the PEVs arrived at home or workplace after an hour of operation, park, and start charging. Table 1 presents self-consumption PEVs charging costs with TOU prices in South Korea. 


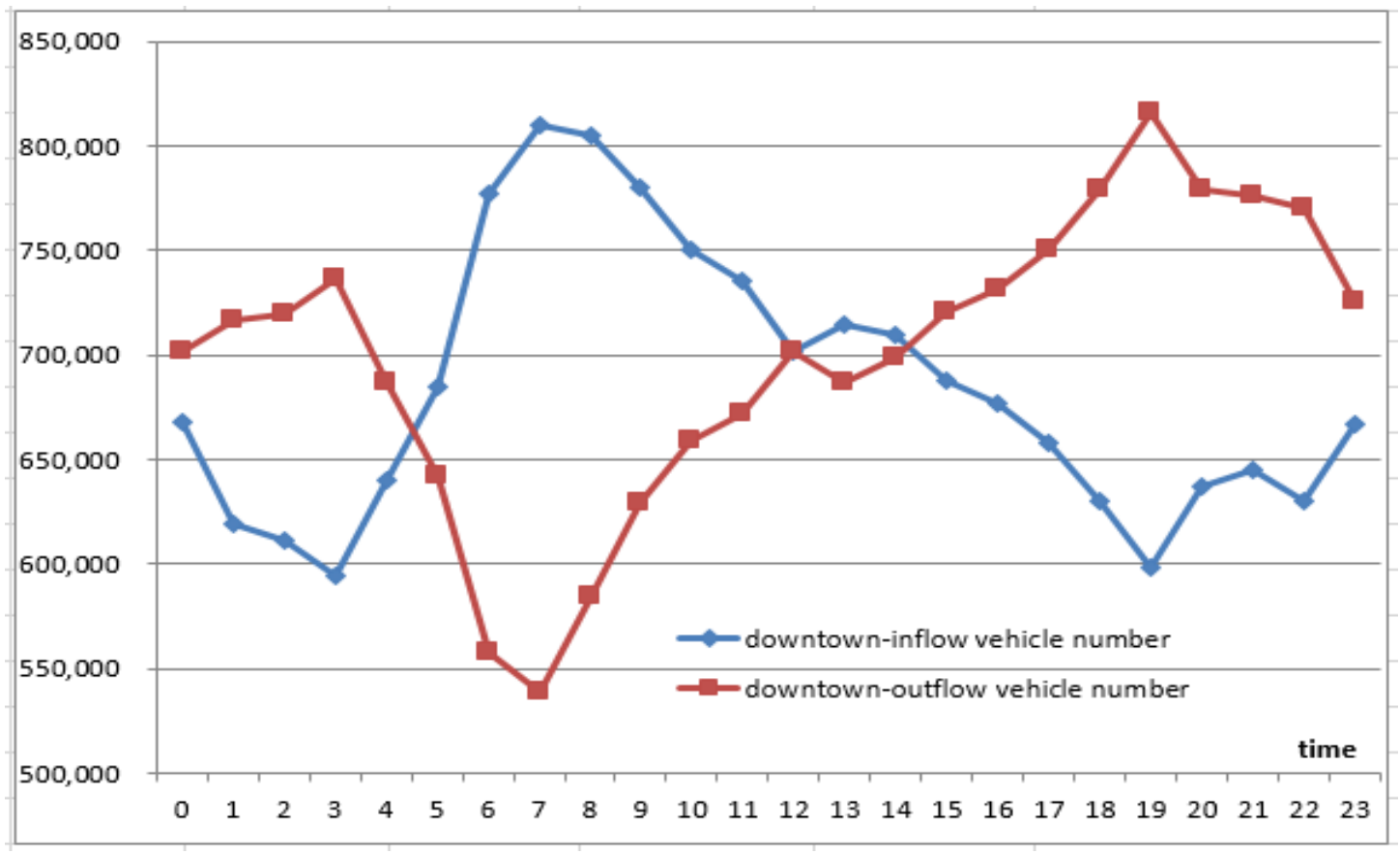

Figure 1. Entry and exit traffic data of vehicles in downtown Seoul, South Korea.

Table 1. Self-consumption PEVs charging cost with TOU tariff.

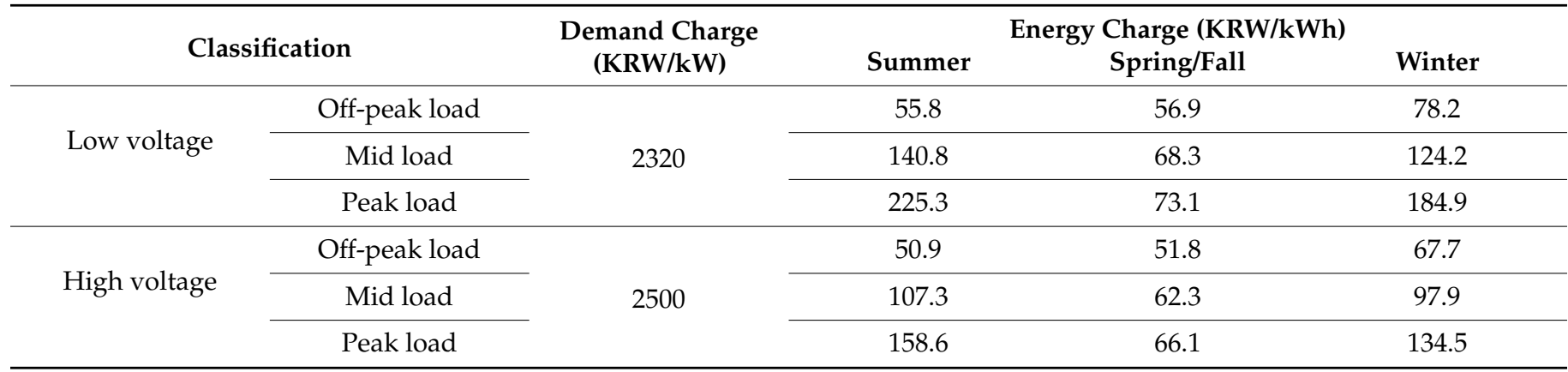

Time-period classification in winter: off-peak (23:00-09:00), peak (10:00-12:00, 17:00-20:00, 22:00-23:00), mid load (other times). Time-period classification in summer and spring/fall: off-peak (23:00-09:00), peak (11:00-12:00, 13:00-17:00), mid load (other times). Source: Electricity tariff structure by Korea Electric Power Company.

\subsection{Probabilistic Density Function of PEVs Charging Start Time at the Workplace}

Figure 2 shows the probability density function for the uncontrolled PEVs charging start time at the workplace. The function is calculated using Equation (1), which takes into account the hourly downtown area entry traffic in the morning and one hour driving time from home to the workplace. In addition, the probability density function for the controlled PEVs charging start time is calculated by Equation (2), which takes into account the entry traffic and TOU prices, as shown in Figure 3.

In Equation (1) and Equation (2), "whole Vehicle(t)" is the total number of vehicles in operation at time $t ; V_{\text {flow_in }}(t+1 \mathrm{~h})$ denotes the number of vehicles entering the downtown area after $1 \mathrm{~h}$ of actual driving time $(t)$; and $V_{\text {flow_out }}(t+1 \mathrm{~h})$ denotes the number of vehicles leaving the downtown area after $1 \mathrm{~h}$ of actual driving time $(t)$. In addition, we note that "time of use" = "charging power rates by time" (TOU). 


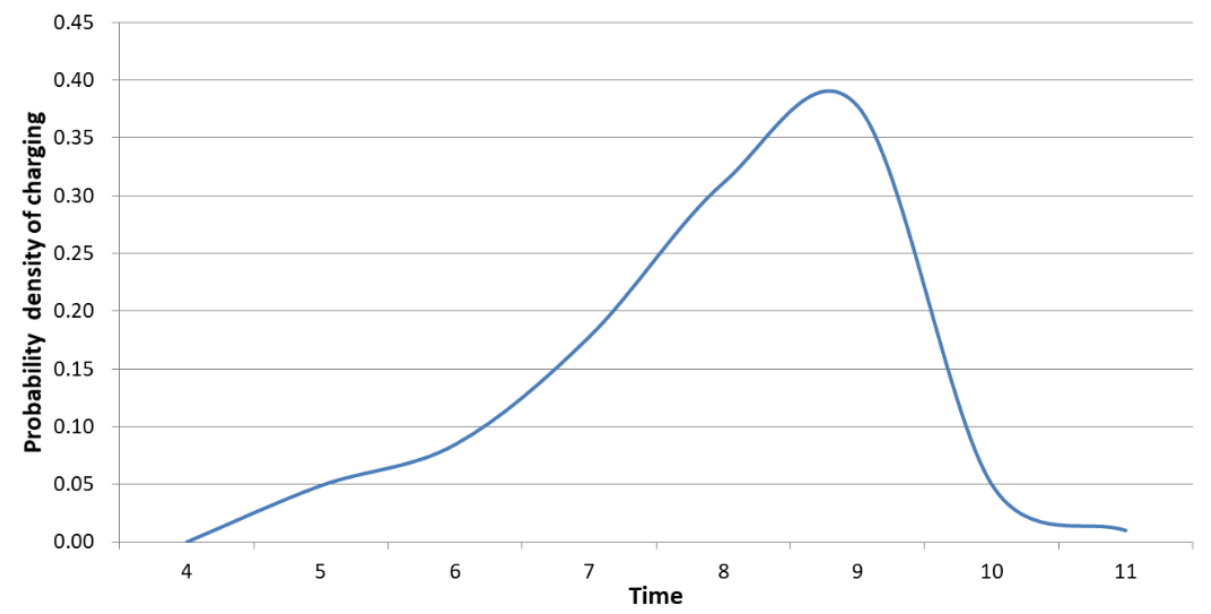

Figure 2. Probability density function for the uncontrolled charging start time in the workplace.

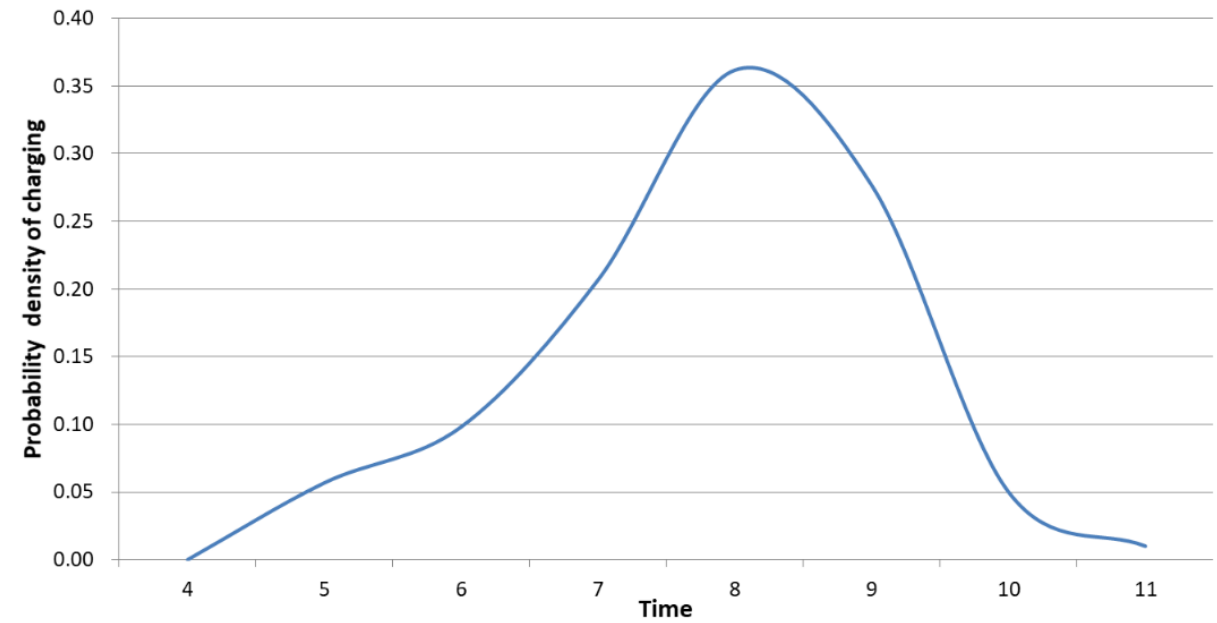

Figure 3. Probability density function for the controlled charging start time in the workplace.

The probability density function for the charging start time in the workplace (uncontrolled mode) is:

$$
P_{u w}(t)=\frac{\left(V_{\text {flow_in }}(t+1 \mathrm{~h})-V_{\text {flow_out }}(t+1 \mathrm{~h})\right)}{\text { whole Vehicle }(t+1 \mathrm{~h})}, \quad(4 \mathrm{~h} \leq t \leq 11 \mathrm{~h})
$$

The probability density function for the charging start time in the workplace (controlled mode) is:

$$
P_{c w}(t)=\frac{\left(V_{\text {flow_in }}(t+1 \mathrm{~h})-V_{\text {flow_out }}(t+1 \mathrm{~h})\right)}{\text { whole Vehicle }(t+1 \mathrm{~h})} /(\text { time_of_use }),(4 \mathrm{~h} \leq t \leq 11 \mathrm{~h})
$$

The rationale behind Equation (1) is that PEVs are likely to be charged in the workplace located downtown within a specific time (e.g., within one hour) after arriving at the workplace. The rationale behind Equation (2) is that PEVs are more likely to be charged if the TOU price is lower after arriving at the workplace.

This research found that the uncontrolled mode's probability density gradually increased from 5:00 to 9:00 in the morning when the probability density functions for the uncontrolled charging start times were analyzed. This increase was followed by a rapid decrease, reaching its maximum at 9:00 in the morning. On the other hand, the controlled mode's probability density gradually increased from 5:00 to 8:00 in the morning. This increase was followed by a rapid decrease reaching its maximum at 8:00 in the morning. 
The difference in the maximums between the uncontrolled and controlled modes is that the TOU prices increase after 9:00 in the morning.

\subsection{Probabilistic Density Function for the PEVs Charging Start Time at Home}

Figure 4 shows the probability density function for the uncontrolled PEVs charging start time at home calculated using Equation (3). The calculation takes into account the hourly downtown exit traffic data in the afternoon, plus one hour driving time from the workplace to home. The probability density function for the controlled PEVs charging start time at home is calculated by Equation (4). The calculation takes into account the hourly exit traffic data and TOU prices, as shown in Figure 5.

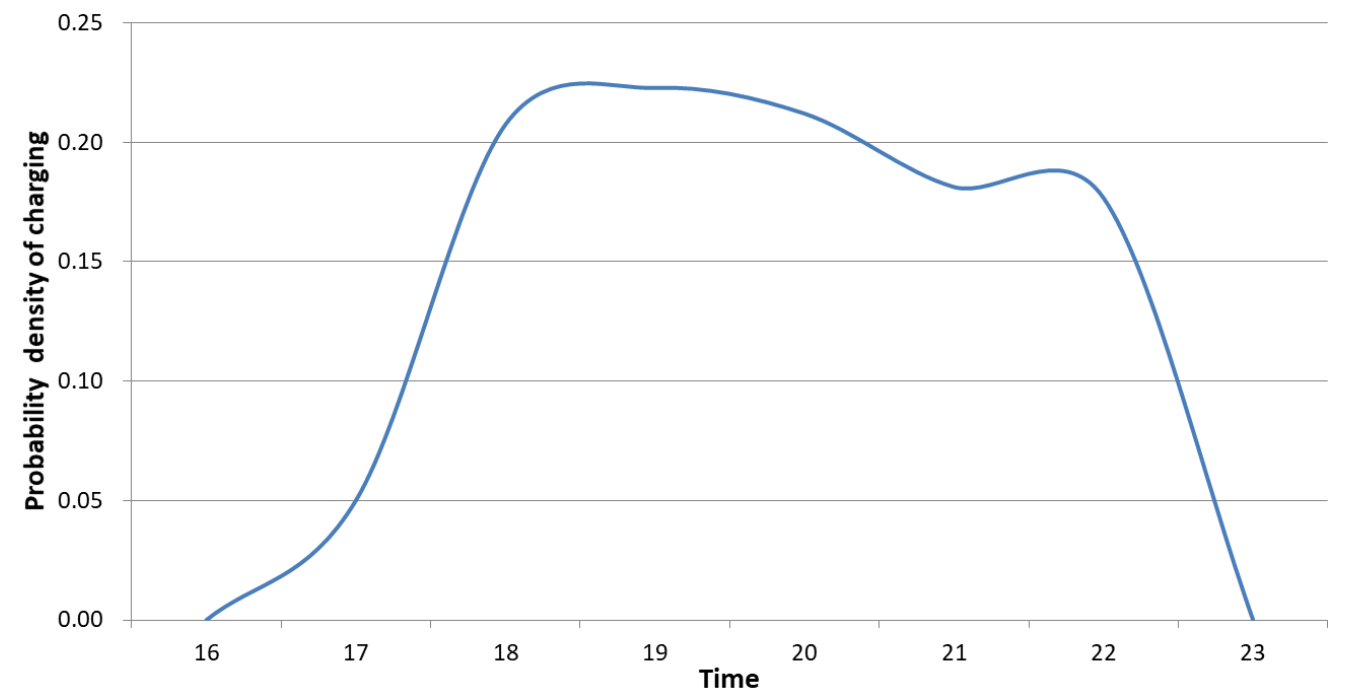

Figure 4. Probability density function for the uncontrolled charging start time at home.

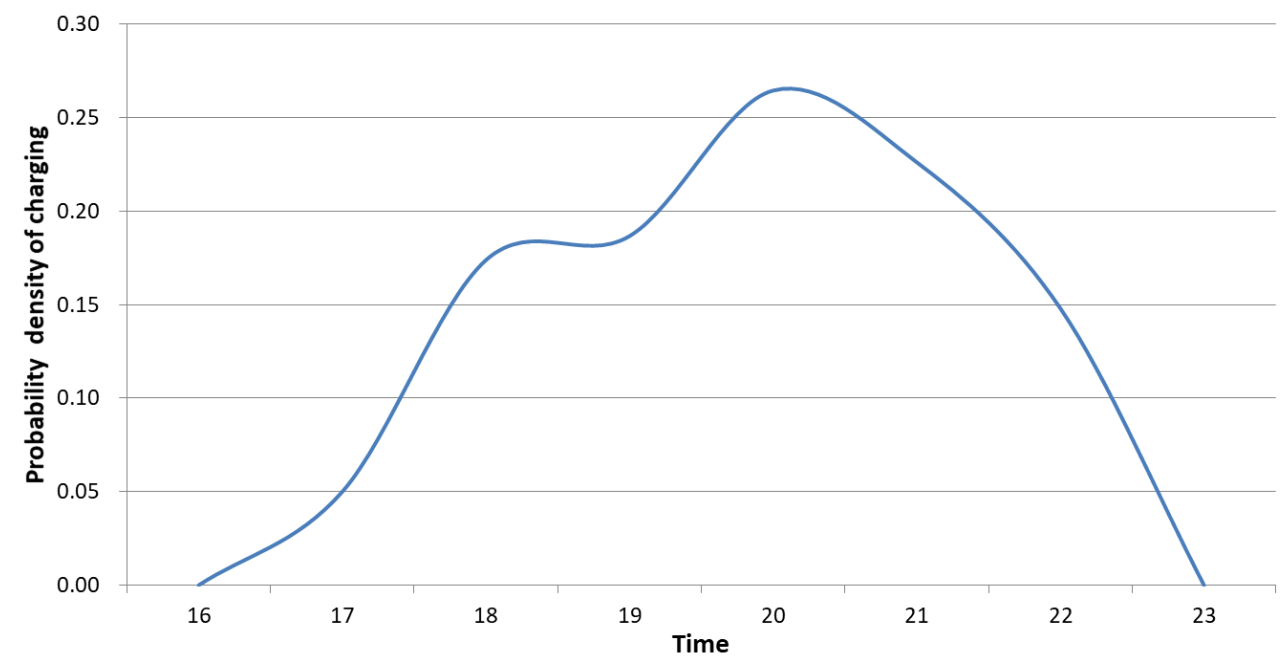

Figure 5. Probability density function for the controlled charging start time at home.

In Equations (3) and (4), whole Vehicle $(t)=$ the total number of vehicles in operation at time $t ; V_{\text {flow_out }}(t+1 \mathrm{~h})=$ vehicles leaving the downtown area after $1 \mathrm{~h}$ of actual driving time $(t) ; V_{\text {flow_in }}(t+1 \mathrm{~h})=$ vehicles entering the downtown area after $1 \mathrm{~h}$ of actual driving time $(t)$. In addition, time of use $=\mathrm{EV}$ charging rates by time $(\mathrm{TOU})$ 
The probability density function for the charging start time at home (uncontrolled mode) is:

$$
P_{\text {uh }}(t)=\frac{\left(V_{\text {flow }_{\text {out }}}(t+1 \mathrm{~h})-V_{\text {flow }_{\text {in }}}(t+1 \mathrm{~h})\right)}{\text { whole Vehicle }(t+1 \mathrm{~h})}, \quad(16 \mathrm{~h} \leq t \leq 23 \mathrm{~h})
$$

The probability density function for the charging start time at home (controlled mode) is:

$$
P_{c h}(t)=\frac{\left(V_{\text {flow }_{\text {out }}}(t+1 \mathrm{~h})-V_{\text {flow }_{\text {in }}}(t+1 \mathrm{~h})\right)}{\text { whole Vehicle }(t+1 \mathrm{~h})} / \text { TOU }, \quad(16 \mathrm{~h} \leq t \leq 23 \mathrm{~h})
$$

The rationale behind Equation (3) is that PEVs are likely to be charged at homes located at the outskirts of the downtown area within a specific time (e. g., within one hour) after the drivers arrive at their homes. The logic behind Equation (4) is that, after arriving at home, the PEVs are more likely to be charged if the TOU prices are somewhat low.

On the other hand, the analysis of the uncontrolled and controlled charging start times' probability density functions (Figures 4 and 5) shows that the probability density of the uncontrolled mode increases gradually from 16:00 to 19:00 and then falls gradually. In particular, we can see that the probability density will reach its highest point at 19:00. However, the probability density of the controlled mode increases gradually from 16:00 to 20:00 and then falls rapidly for the controlled mode. In particular, we can see that it reaches its peak at 20:00. The uncontrolled and controlled modes' peak times are different because the TOU prices are lowered until 20:00.

\subsection{Calculation of the Initial SOC of a PEVs Battery}

The initial battery SOC at the time of going from home to work and vice versa is calculated by Equation (5), which considers the mean driving distance predetermined for PEVs charging.

$$
\operatorname{soc}_{0}=\left(1-\frac{\alpha}{d_{R}}\right) \times 100 \%
$$

where $\alpha$ is the daily driving distance, and $d_{R}$ is the maximum driving distance of the PEVs.

A daily driving distance of $46.2 \mathrm{~km}$ from home to work and vice versa was used to calculate the initial battery $S O C_{0}$ based on a charging station in Seoul using Equation (5). The distance was obtained from the 2010 Vehicle Driving Distance Analysis Report [15] published by the Seoul Metropolitan Police Agency. Meanwhile, the PEVs maximum driving distance was set to $180 \mathrm{~km}$ according to PEVs efficiency of $0.16 \mathrm{kWh} / \mathrm{km}$ [16] when using a Nissan Altra 29-kWh lithium-ion battery. We have used constant values for the initial $S O C_{0}$ and charging times for each electric vehicle because we applied the average values for evaluating the daily load patterns for charging electric vehicles on a large scale, like a big city.

Therefore, based on the $46.2-\mathrm{km}$ daily driving distance from home to work and vice versa, the initial battery $S O C_{0}$ at the time of starting from home to work and vice versa was calculated as $74 \%$. Therefore, the initial battery $S O C_{0}$ after two days of driving would be 0.49 if the initial battery $S O C_{0}$ is high enough to not require recharging after one day of driving from home to work and vice versa and needs recharging after two days of driving the same distance.

Accordingly, the charging time $T_{c}(\mathrm{~h})$ in the workplace and at home for the Nissan Altra lithium-ion battery can be calculated by Equation (6). In this equation, the initial battery state of charge $=S O C_{0}$ and the final battery state of charge $=S O C_{F}$. In summary, the PEV battery $S O C_{F}$ was set to 1, indicating a full charge. In contrast, the hourly battery charging power $\left(B_{C}\right)$ was set to $6.0 \mathrm{~kW}$ based on the hourly charging power nature of the Nissan Altra lithium ion-battery. Therefore, $T_{c}(\mathrm{~h})$ in the workplace and at home was determined to be $5.0 \mathrm{~h}$. The initial $S O C_{0}$ and the charging time of all PEVs in Equation (5) 
and Equation (6) are the same because it was assumed that all vehicles had the same initial $S O C_{0}$ and average mileage for the analysis purposes of the daily load patterns of PEVs charging on a large scale such as in a big metropolitan area.

$$
T_{c}=\frac{\left(S O C_{F}-S O C_{0}\right)}{B_{C}} \times 29 \mathrm{kWh}
$$

\section{Results}

\subsection{Case Study to Calculate Daily Load Patterns}

A daily load pattern for a single PEVs battery charging was calculated according to the probability density function of the uncontrolled and controlled hourly charging start times in the workplace and at home, the initial PEVs battery $\mathrm{SOC}_{0}$, the charging time, and hourly charging power. These are indicated in the charging model algorithm per PEVs charging station discussed in Sections 2.1-2.3.

According to the Seoul Metropolitan Government plan, the predicted PEVs' market shares in 2030 and 2040 were $10 \%$ and $30 \%$ of the total number of vehicles, respectively. This study used this prediction to evaluate the number of PEVs. These data were used to calculate the daily load patterns of a single PEVs charging session to estimate the daily load patterns of the total uncontrolled and controlled PEVs charging in the workplace and at home in Seoul. Furthermore, the existing daily load patterns in Seoul were calculated based on the customer's electric load pattern [17], as published by the Korea Energy Management Corporation (2020) (Figure 6).

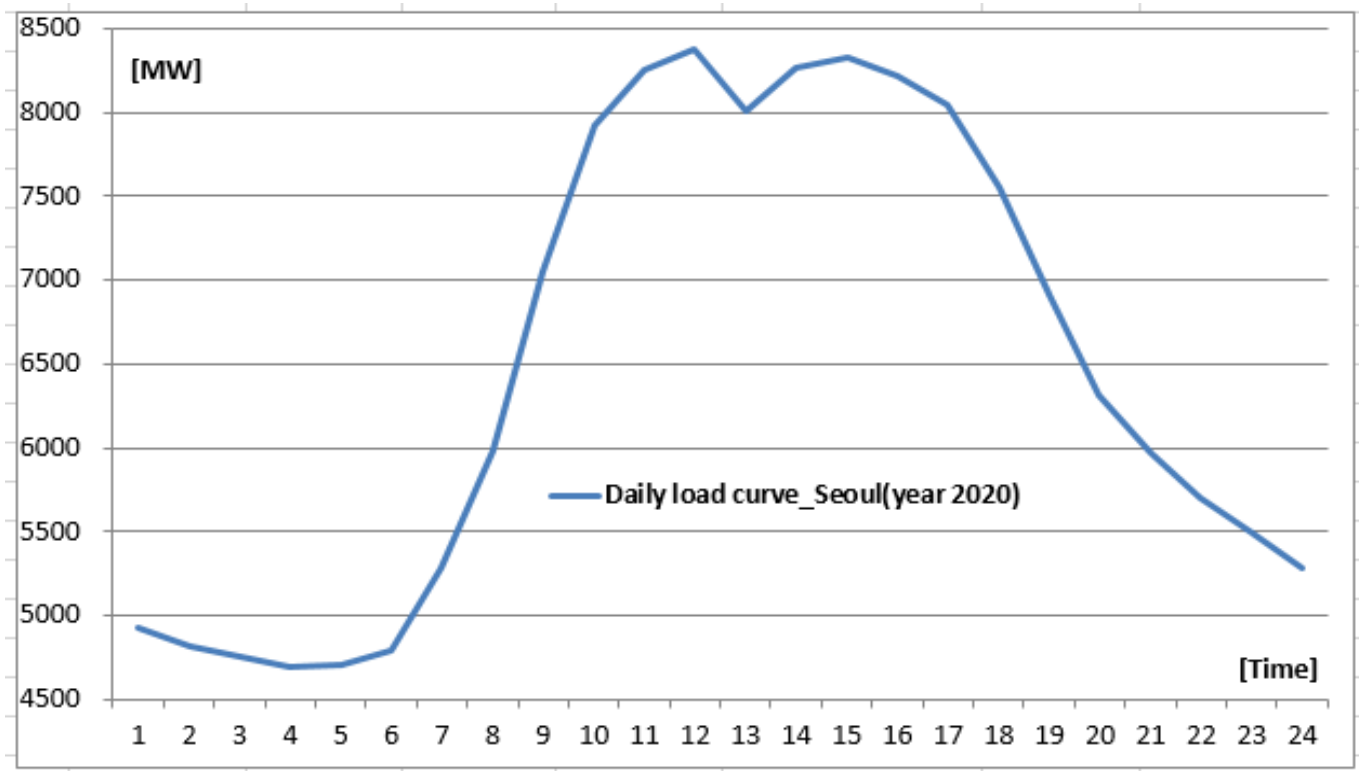

Figure 6. Existing daily load patterns in Seoul in 2020.

In addition, based on Figure 6, the load increase trend technique was applied to estimate the existing daily load patterns in Seoul in 2030 and 2040. Subsequently, this projection was added to the daily load patterns of the uncontrolled and controlled PEVs charging in the workplace and at home calculated on the basis of the charging probability density function per PEV charging station, as shown in Figures 2-5. The results were used to predict the daily load patterns of the total uncontrolled and controlled PEVs charging modes in Seoul in 2030 and 2040, as shown in Figures 7-10. Figure 11 shows an overall flowchart. 


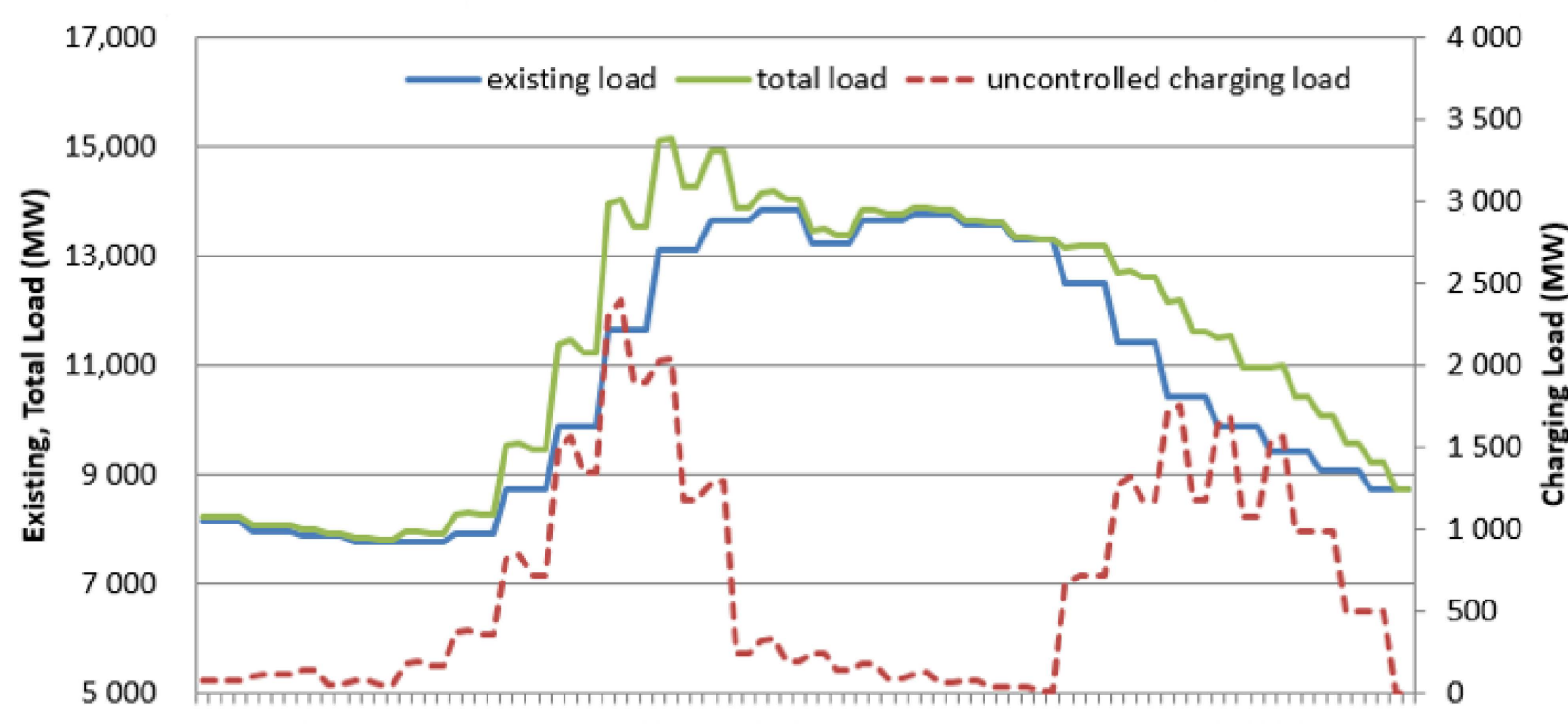

$\begin{array}{llllllllllllllllllllllll}1 & 2 & 3 & 4 & 5 & 6 & 7 & 8 & 9 & 10 & 11 & 12 & 13 & 14 & 15 & 16 & 17 & 18 & 19 & 20 & 21 & 22 & 23 & 24\end{array}$

Time

Figure 7. Daily load patterns of the total uncontrolled charging mode in Seoul in 2030.

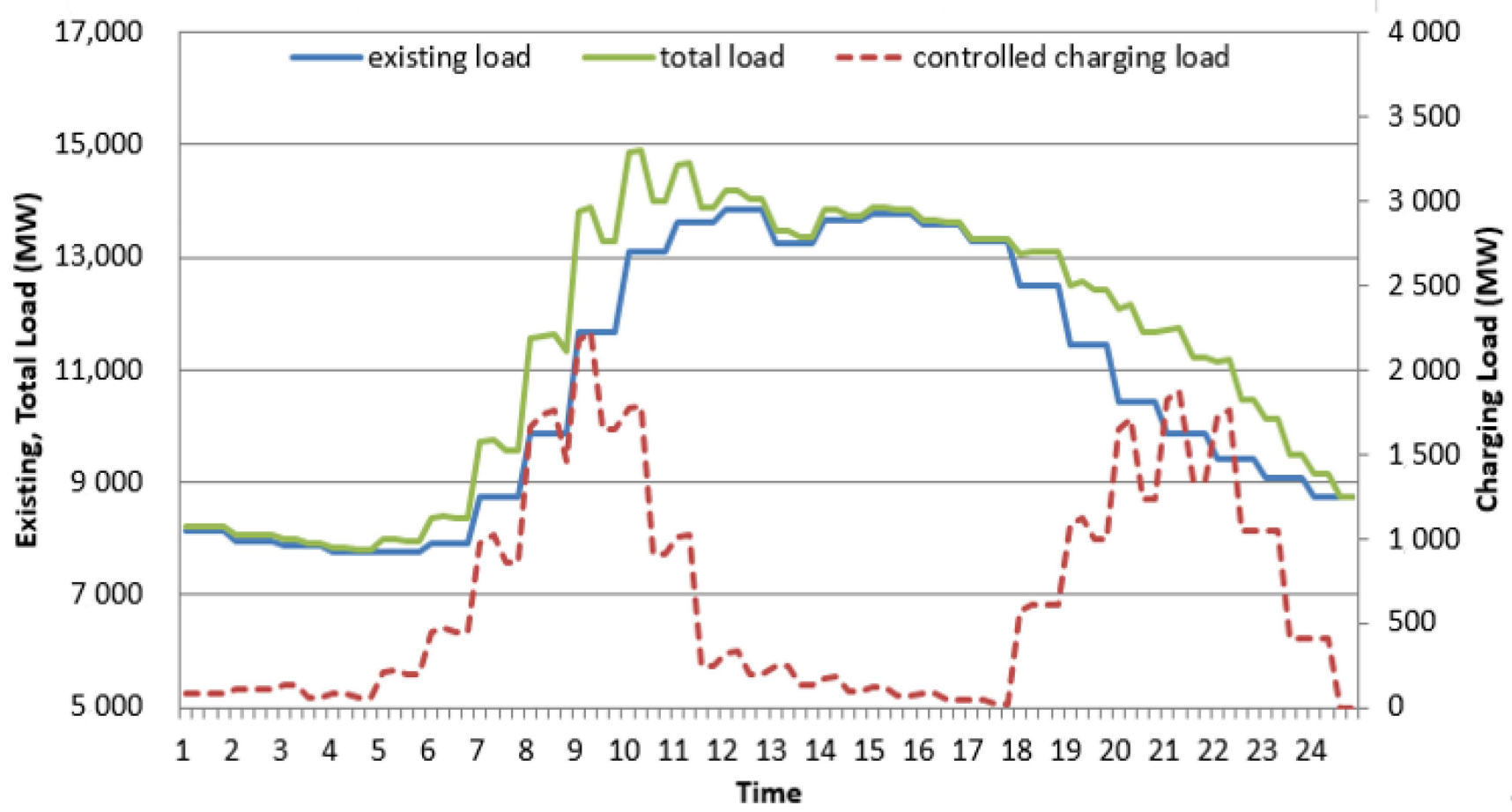

Figure 8. Daily load patterns of the total controlled charging mode in Seoul in 2030. 


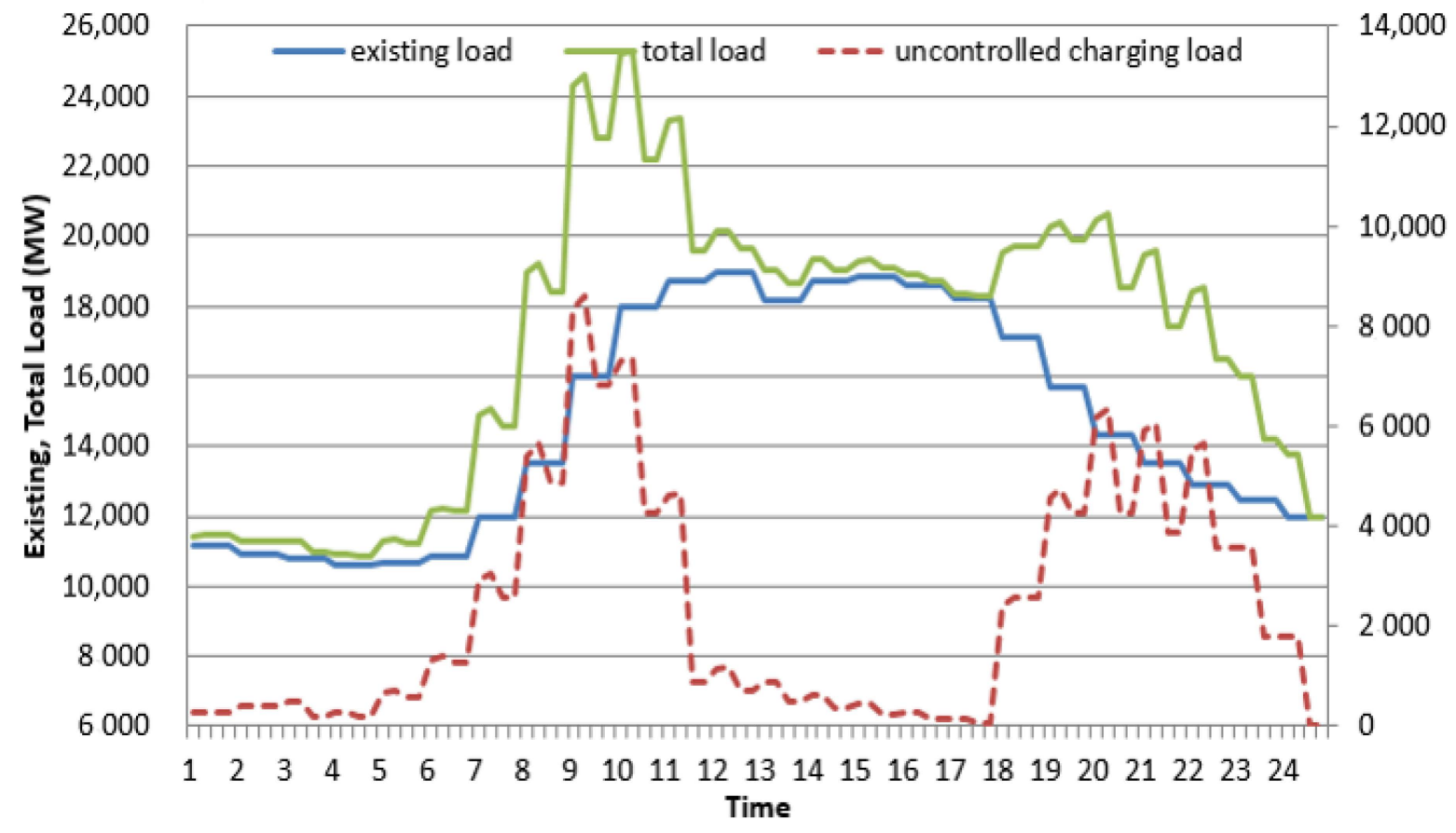

Figure 9. Daily load patterns of the total uncontrolled charging mode in Seoul in 2040.

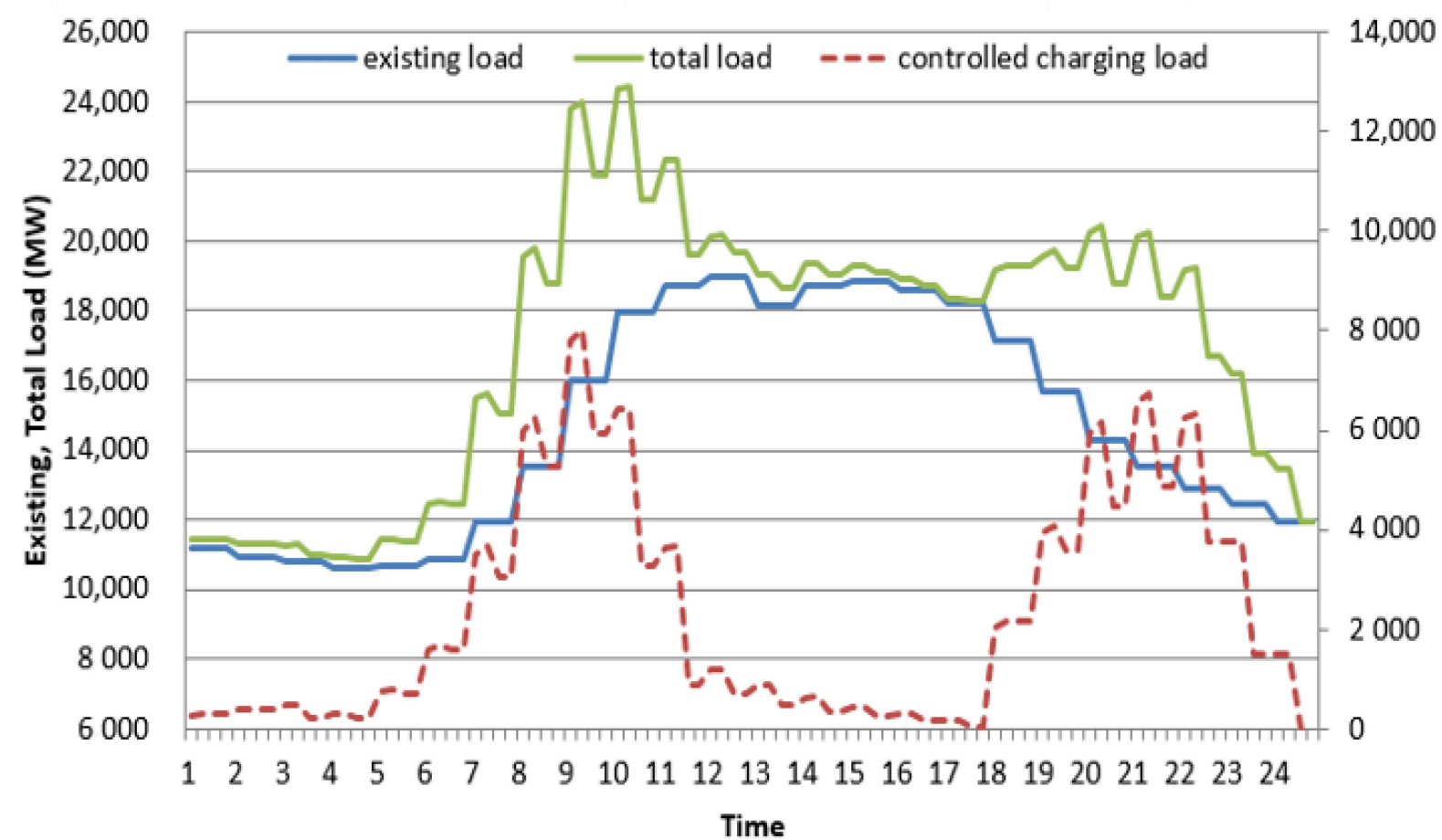

Figure 10. Daily load patterns of the total controlled charging mode in Seoul in 2040. 


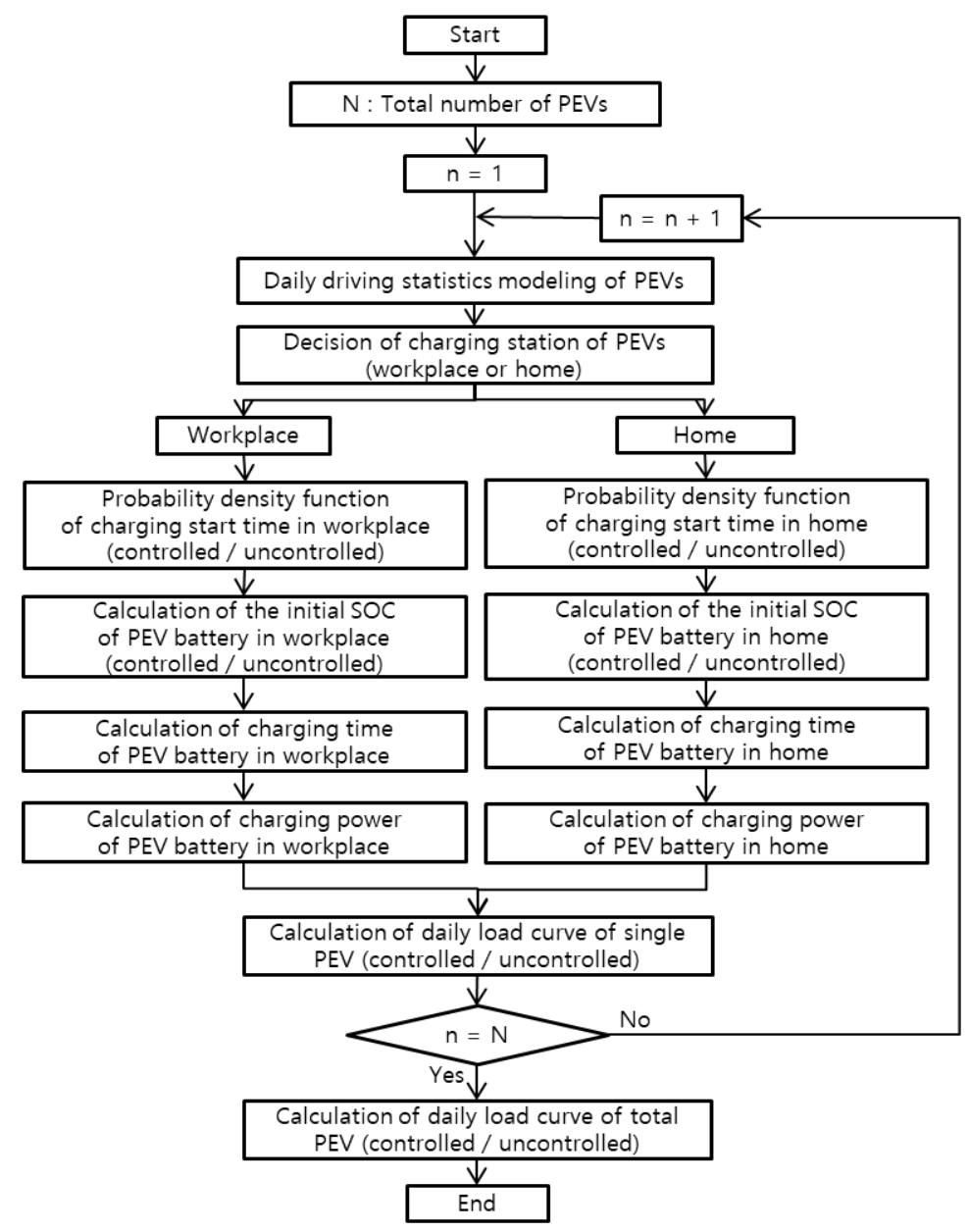

Figure 11. Flowchart to calculate the daily load patterns of the total PEVs.

\subsection{Analysis of the per Charging Station Effect of PEVs on the Power Grid}

The daily load patterns of the uncontrolled and controlled PEVs charging modes in Seoul were calculated based on the PEVs predicted market shares in 2030 and 2040 based on the Seoul Metropolitan Government plan. The analysis results are presented below. The daily existing load curves in 2030 and 2040 increase gradually from 6:00, decrease slightly between noon and 13:00, which is lunchtime, increase from 13:00, peak at around 14:00, and decrease gradually from 18:00.

In contrast, the daily load patterns per charging station of the uncontrolled and controlled PEVs charging modes in 2030 and 2040 show the following results. First, the uncontrolled charging mode's daily load patterns in the workplace show that the charging load starts at 5:00, followed by a gradual increase that peaks at 9:00, and a decrease after that. The controlled mode's charging load increases from 5:00 in the morning similar to the uncontrolled mode, followed by a rapid increase. It peaks at 9:00 and gradually decreases after that.

Second, the PEVs charging's daily load patterns at home in the uncontrolled charging mode show a gradual increase from 18:00. They peak at 20:00, and decrease after that. The controlled charging mode shows a gradual increase from 18:00 similar to uncontrolled charging mode. It peaks at 22:00, and a decrease after that. For the controlled mode, the TOU price is affected by the charging peak time at home from 22:00 in winter, as shown Table 1.

In addition, comparing the workplace charging loads in the morning and the home charging loads in the evening shows that the workplace charging load is slightly higher than at home after work. This is because the number of vehicles traveling from home to the workplace in the morning is higher than the number of vehicles returning from the 
workplace to home in the afternoon. Thus, some of the vehicles may not return home in the afternoon.

The following results are obtained for the total daily load patterns of the uncontrolled and controlled charging modes in 2030 and 2040. First, when the PEVs' market share is $10 \%$ in 2030, the uncontrolled and controlled modes' total charging loads in the workplace and at home are not large: compared to the existing load, the total load increases by about 13\% between 9:00 and 11:00 in the morning for the uncontrolled mode and by about 10\% for the controlled mode. The total load increases by about 16\% between 20:00 and 22:00 for the uncontrolled mode and $17 \%$ for the controlled mode. The analysis showed that it was possible to achieve a load-leveling effect in all charging periods for the controlled mode, with the daily load pattern's average leveling rate increasing by $8 \%$ based on the TOU price plan compared with the uncontrolled mode. Here, the load-leveling effect was calculated by applying the difference between the maximum load and the minimum load based on the sum of the maximum and minimum loads over time.

Second, when the PEVs market share is $30 \%$ in 2040, the uncontrolled and controlled modes' total charging loads in the workplace and at home increase significantly: compared to the existing load, the total load increases by about $35 \%$ between 9:00 and 11:00 in the morning for the uncontrolled mode and by about $32 \%$ for the controlled mode. Between 20:00 and 22:00, the uncontrolled mode's total charging load increases by about $35 \%$ and the controlled mode's total load by about $32 \%$. The analysis also demonstrated that it was possible to achieve a significant load-leveling effect in all charging periods for the controlled mode, with the average leveling rate increasing by $13 \%$ based on the TOU price system compared with the uncontrolled mode.

\section{Conclusions}

This paper presented the calculation of daily load patterns of PEVs charging per charging station in Seoul, South Korea, and presented a method of adding the calculated results to the existing daily load patterns. More specifically, this study calculates the daily load patterns of PEVs charging based on PEVs charging conditions (in the workplace in the morning and at home in the afternoon and evening) and the number of PEVs predicted based on their increased market share in 2030 and 2040. This research also classified PEVs charging modes into uncontrolled and controlled. The uncontrolled charging mode is based on the number of vehicles operated per hour, and the controlled charging mode takes into account the TOU price plan and that number. Furthermore, this study obtained the total daily load patterns of the uncontrolled and controlled charging modes in Seoul per year by adding the abovementioned daily load patterns to the existing daily load patterns.

Since this paper calculates the daily load patterns according to the current TOU prices in Seoul, additional research on the TOU price plan will be conducted to maximize the flattening effect of the daily load patterns by leveling the charging load by period according to the PEVs market share increase.

The daily charging load curves of PEVs in the workplace and at home in Seoul can be calculated based on the current TOU price using the results presented in this paper. This calculation can be utilized to establish a TOU price plan management scheme to prevent the overload of power grids in Seoul. We, therefore, arrived at the following conclusions. First, the existing load increased gradually from 6:00 in the morning, decreased slightly from noon to 13:00, increased from 13:00, peaked at 14:00, and increased gradually from 18:00.

Second, the daily charging load curves of PEVs in the workplace showed that the charging load started to increase gradually from 5:00 and peaked at 9:00 in the morning. A gradual decrease followed after that time. The controlled mode's charging load increased from 5:00 in the morning similar to the uncontrolled mode, followed by a rapid increase. It peaked at 9:00 and gradually decreased after that.

The controlled charging mode's load increased from 5:00 similar to the uncontrolled charging mode, followed by a rapidly increase until 9:00 in the morning, followed by a gradual decrease. 
Third, the PEVs charging's daily load patterns at home in the uncontrolled charging mode showed a gradual increase from 18:00. They peaked at 20:00, and decreased after that. The controlled charging modes showed a gradual increase from 18:00 similar to the uncontrolled charging mode. They peaked at 22:00, and decreased after that. For the controlled mode, the TOU price is affected by the charging peak time at home from 22:00 in winter, as shown Table 1.

Fourth, in the case of the $10 \%$ market share of PEVs in 2030, the uncontrolled and controlled modes' total charging loads in the workplace and at home were not large: compared to the existing load, the total load increased by about 13\% between 9:00 and 11:00 in the morning for the uncontrolled mode and by about $10 \%$ for the controlled mode. The total load increased by about 16\% between 20:00 and 22:00 for the uncontrolled mode and $17 \%$ for the controlled mode. The analysis showed that it was possible to achieve a load-leveling effect in all charging periods for the controlled mode, with the daily load pattern's average leveling rate increasing by $8 \%$ based on the TOU price plan compared with the uncontrolled mode.

Fifth, in the case of the 30\% market share of PEVs in 2040, the uncontrolled and controlled modes' total charging loads in the workplace and at home increased significantly: compared to the existing load, the total load increased by about 35\% between 9:00 and 11:00 in the morning for the uncontrolled mode and by about $32 \%$ for the controlled mode. Between 20:00 and 22:00, the uncontrolled mode's total charging load increased by about $35 \%$ and the controlled mode's total load by about $32 \%$. The analysis also demonstrated that it was possible to achieve a significant load-leveling effect in all charging periods for the controlled mode, with the daily load patterns' average leveling rate increasing by $13 \%$ based on the TOU price system compared with the uncontrolled mode.

Lastly, since it is clear that the local energy production will increase in metropolitan areas in the future, a study could be prepared through additional research once a plan for local energy production for the next 10-20 years is confirmed, including specific PV power generation plans for each building in Seoul city.

Author Contributions: Conceptualization, S.C.; Methodology, C.K.; Software, B.S.; Validation, S.C.; Investigation, S.C.; Resources, S.C., C.K. and B.S.; Data curation, C.K.; Writing-original draft, S.C.; Writing-review and editing, S.C., C.K. and B.S.; Supervision, S.C. All authors have read and agreed to the published version of the manuscript.

Funding: This research was funded by the Korea Institute of Energy Technology Evaluation and Planning (Grant No. 20192010107050).

Institutional Review Board Statement: Not applicable.

Informed Consent Statement: Not applicable.

Data Availability Statement: Data sharing not applicable.

Conflicts of Interest: The authors declare no conflict of interest.

\section{References}

1. EPRI. A Technical Overview of Transportation Electrification; EPRI Technical Report; EPRI: Washington, DC, USA, 2011.

2. Qian, K.; Zhou, C.; Allan, M.; Yuan, Y. Modeling of Load Demand Due to EV Battery Charging in Distribution Systems. IEEE Trans. Power Syst. 2010, 26, 802-810. [CrossRef]

3. Clements-Nyns, K.; Haesen, E.; Driesen, J. The impact of charging plug-in-hybrid electric vehicles on a residential distribution grid. IEEE Trans. Power Syst. 2010, 25, 371-380. [CrossRef]

4. Zhao, L.; Prousch, S.; Hubner, M.; Moser, A. Simulation methods for assessing electric vehicle impact on distribution grid. In Proceedings of the IEEE PES Transmission and Distribution Conference and Exposition, New Orleans, LA, USA, 19-22 June 2010.

5. Son, H.; Kook, K. Stochastic modeling of plug-in hybrid vehicle distribution in power systems. JEET 2013, 8, 125011636.

6. Choi, S.B. Load variation analysis by bus of distribution systems based on PEVs charging modeling. Electr. Eng. 2018, 100, 687-694. [CrossRef]

7. Choi, S.B. Analysis for evaluating the impact of PEVs on New-Town distribution system in Korea. JEET 2015, 10, 859-864. [CrossRef]

8. Zhipeng, L.; Fushuan, W. Optimal siting and sizing of electric vehicle charging station. Autom. Electr. Power Syst. 2012 , 3, 54-59. 
9. Cao, Y.; Tang, S.; Li, C.; Zhang, P.; Tan, Y.; Zhang, Z.; Li, J. An Optimized EV Charging Model Considering TOU Price and SOC Curve. IEEE Trans. Smart Grid 2011, 3, 388-393. [CrossRef]

10. Masoum, A.S.; Deilami, S. Smart load management of plug-in electric vehicles in distribution and residential networks with charging stations for peak shaving and loss minimization considering voltage regulation. IET Gener. Transm. Distrib. 2012, 8 , 877-888. [CrossRef]

11. Datchanamoorthy, S.; Kumar, S. Optimal Time of use Pricing for Residential Load Control. In Proceedings of the Smart Grid Communications, Brussels, Belgium, 17-20 October 2012; pp. 375-380.

12. Saliah, J.T. Energy requirements for electric cars and their impacts on electric generation and distribution systems. IEEE Trans. Ind. Appl. 1973, 1A-9, 516-531. [CrossRef]

13. Seoul Metropolitan Police Agency. 2012 Seoul City Traffic Survey. 2013.

14. KEPCO Electric Vehicle Charging TOU Tariff. 2020. Available online: https:/ /Cyber.kepco.co.kr. 2020, 9, 5.

15. 2010 Analysis for Actual Condition Survey of Vehicle Mileage. Seoul Traffic Safety Complex. 2011, 10, 22.

16. Department for Business Enterprise and Regulatory Reform (BEER); Department for Transport. Investigation into the Scope for the Transport Sector to Switch to Electric Vehicles and Plug-In Hybrid Vehicles; BEER: London, UK, 2008; p. 10.

17. Korea Energy Management Corporation. 2020 Analysis of Electric Load Curve by Customer in Korea. $2020,5,18$. 